\title{
Research on Performance Management of Administrative Departments in Colleges and Universities
}

\author{
Yifei Gou \\ Xi'an Shiyou University, Xi'an, Shaanxi, 710065
}

Keywords: Administrative Departments in colleges and universities; performance management; efficiency improvement

\begin{abstract}
The administrative departments of colleges and universities have important implications for the management of colleges and universities and their daily work. The ability of their administrative departments also determines their own competition and development abilities. To establish a good university, the administration of the university plays a decisive role. Therefore, it is necessary to strengthen the construction of colleges and universities, do a good job in the performance management of the administrative departments in colleges and universities and establish a sound performance management system. This paper studies and analyzes the related issues of the performance management of administrative departments in colleges and universities.
\end{abstract}

\section{Introduction}

The administration of colleges and universities is an important part of personnel work in colleges and universities, and it is also an important foundation and guarantee for guaranteeing school teaching, scientific research and daily work. At this stage, the personnel management system in universities is constantly reforming and changing, and the performance management of the administrative departments of universities has also become a key task. The following sections analyze the problems existing in the performance management work of the administrative departments of universities in China at the current stage and the key contents and measures for doing a good job of performance management.

\section{The Importance of Performance Management of Administration Departments in Colleges and Universities}

The performance management of university administrators refers to the realization of the development strategy and goals of universities, adopting scientific methods, and fully mobilizing the enthusiasm of administrative staff through the comprehensive monitoring, analysis and evaluation of the administrative staff's work attitude and work performance as well as the overall quality. Initiative and creativity, continuously improving the behavior of administrative staff and tapping their potential activities. Performance evaluation is an important part of performance management and an indispensable management tool and powerful tool for administrative performance management in universities. Raising the efficiency of each employee through performance appraisal ultimately guarantees the implementation of the management goals of the school. The school has three elements - administration, education, and research. Among the three elements, administrative management is the basis for the university to realize its two major social functions of teaching and research. With the deepening of China's higher education reform, the development of colleges and universities is facing a new situation. As a gathering place for high-quality talents, promoters of scientific and technological innovation activities, and disseminators of advanced culture, colleges and universities should use advanced management concepts and scientific management methods, including performance management, to conduct administrative management. It not only has an exemplary role in society, but also Can increase the competitiveness of the school itself, and comprehensively improve the level of university administration. Through the implementation of performance management of administrative offices 
in colleges and universities, it is also an important way to improve the quality of administrative staff throughout the university. It can ultimately promote and guide the individual development of schools and staff to achieve a win-win situation, improve the overall competitiveness of universities, and achieve the development of the school. Strategic objectives.

\section{Problems Existing in Performance Management of Administration Departments in Colleges and Universities}

At this stage, colleges and universities in order to accelerate their own development and improve their influence and visibility, they themselves continue to establish long-term development plans, annual plans and other development goals. At the same time, in the process of formulating various long-term plans, the corresponding performance appraisal has not changed, and it cannot adapt to the development strategies of universities. The corresponding staff assessment mechanism is relatively general and has not been combined with the development strategy of the university. The administrative performance appraisal of colleges and universities should be based on the development plans of universities and colleges, and be distributed according to the university's work plan to form a scientific and effective appraisal system and system. The assessment system needs to be adjusted in accordance with the development strategy and changes in the universities and improve the effectiveness of the assessment work.

At present, the performance appraisal system of the administrative departments of Chinese universities is not appropriate. At present, the system of appraisal and classifying of the past is still used, and it is not possible to carry out grading evaluation and management of the functions and positions of appraisers. For some job evaluation criteria can not meet the objective and accurate requirements, a unified evaluation criteria can not be an accurate assessment of the performance of the administrative work. The evaluation and assessment system at the present stage is too subjective and cannot reflect the performance and level of the work in a quantitative form. The assessment is too formal and cannot achieve the intended purpose. Because of the low level of quantification of performance appraisal management of internal administrative personnel in universities, and the lack of objective evaluation criteria, the appraisal and evaluation work is mainly based on subjective evaluations, and the appraisal credit is low, resulting in inaccurate appraisal results and large errors. In the assessment, some of the assessments are prone to oversight, and no one can be punished. It is impossible to evaluate the administrative staff's own performance scientifically and objectively. Inaccurate appraisal and assessment will have an impact on the actual workforce and will be detrimental to the management.

\section{Strengthening Key Points of Performance Management of Administration Departments in Colleges and Universities}

At present, the administrative evaluation work of colleges and universities in our country is still in the initial stage. People's recognition of the performance appraisal system still remains in the traditional consciousness, and it is believed that the results of the evaluation will not have any impact on the individual. Performance appraisal work is a meaningful task that can effectively reflect the working level of each individual. The result of the corresponding assessment is the display of the working ability of the working staff, and is also the basis of rewards and punishments. For those who do not have good evaluation results, they should combine the results of the assessment with the performance of the work at the time, and make certain improvements so as to improve their working ability.

In order to clearly divide the evaluation system, it should establish a post management responsibility system to formulate reasonable assessment criteria, plan the main tasks of the post management, and measure and manage the tasks, responsibilities, and objectives of the job. Through detailed explanation of the positions, each staff member is made aware of his work responsibilities and work scope. Through the post management responsibility system, the administrators of universities and colleges can strictly request themselves in the work, 
conscientiously complete the work objectives, and objectively complete their own work within the division. Moreover, the post management system is also conducive to the implementation of the performance evaluation system, so that the performance appraisal system can play an effective role in improving the administrative level of university administrative management staff.

The key to the performance evaluation is the scientific nature of the performance evaluation system. At the current stage, the majority of university administrative managers use subjective assessment forms. This form is too subjective and does not accurately reflect the actual work situation and effectively reflect the evaluation results. In the evaluation of personnel, the evaluation system should be formulated in conjunction with the evaluation objectives, and different evaluation systems should be established for managers at each level. The management staff of the upper and middle levels should conduct evaluations in the form of subjective assessments, and the grass-roots management personnel should adopt the corresponding assessment form of objectivity. Through the flexible assessment system, it is possible to effectively evaluate the performance of the entire administrative department, and effectively enhance the efficiency of the work.

\section{Improve the Measures for Performance Appraisal of Administration Departments in Colleges and Universities}

On the basis of careful analysis of the problems in the performance management of college management personnel in China and the key factors affecting the effectiveness of university performance management, based on the performance evaluation principles of fairness, openness, objectivity, combined rewards and punishments improvement, and how to improve the characteristics of colleges and universities, On employee performance appraisal work, talk about the following views. Assessment indicators must be clear and quantified. Content is vague and difficult to grasp. Can not quantify difficult to compare. The system clauses and assessment standards cannot be plausible and generalized. They must be both principled and qualitative. They must have concrete, quantifiable, and operable content. When quantifying, it should reflect the size of the contribution and the performance. Assessment indicators should be comprehensive and performance evaluation should be objective. It is necessary to perform performance appraisal according to the requirements of "Germany, energy, diligence, performance, and integrity"; it is necessary to perform all-dimensional and multi-dimensional performance appraisal of the appraisers. The information of the appraisers is obtained from the multi-participants who have a working relationship with the appraisers. The sources of feedback include: superiors, subordinates, co-workers, clients, collaborative departments, clients, and feedback from themselves.

The contents of the assessment must be comprehensive and specific, but also highlight the key points and reflect it quantitatively. The content of the assessment of college management personnel can be roughly divided into five aspects: German, energy, diligence, performance, and honesty. In addition to examining the ideological and political performance of the appraiser, the so-called "German" should focus on the service attitude and service quality of the appraiser. Management is service. As managers of colleges and universities, we must overcome the "government-based" ideology, strengthen service awareness, consciously change from the role of the past manager to the role of the service provider, strive to serve teachers and students, serve the school's teaching, research; the so-called "energy", In addition to examining the administrative management capabilities of the appraisers and their mastery of modern science and technology, it is also necessary to examine the innovation ability, team awareness, and cooperation capabilities of the appraiser; the so-called "difficulty" mainly examines whether a person can earnestly and diligently work. . "Performance" mainly assesses the performance of the personnel performing the duties and the quantity, quality and efficiency of the work done; "Lian", as the name implies, examines whether a person can be honest and self-discipline, and the public and private are distinct. In the above five aspects, they are related to each other, affect each other and promote each other. Neither waste nor balance. We must adhere to the principle of taking Germany as the lead and performance as the main principle. "German" is the driving force of dedication and enterprise, "energy" is the guarantee for doing a good job, "diligence" is a consistent requirement, "performance" is the 
foothold in which a person's overall quality embodies, and "integrity" is The most basic conduct of personnel. Therefore, when formulating assessment quantitative indicators, we should focus on daily tasks and work items, highlight "performance," and distinguish the contribution of different jobs and their role in performance management, and quantify them by giving them different weights. . For example, a performance appraisal system is designed for a department that is mainly responsible for day-to-day management affairs, including overall impression evaluation (mainly for undergraduate staff appraisal, leadership appraisal), performance of duties (mainly through work discipline, daily work), job performance, and attendance. Four aspects to evaluate, we quantify by scoring, a total score of 150 points. Since the tasks handled by the department are mostly daily tasks, the "performance of duties" can be divided into 60 points, 40 points for impression evaluation, 30 points for work performance, and 20 points for attendance. The specific content of each item can be given different weights when quantifying its importance. For example, in the "Overall Impression Evaluation", the department staff should have a greater say, and the evaluation can account for $60 \%$ of the impression evaluation score, that is, $40 \times .60 \%=24$ points; of course, for different administrative departments, different departments should be based on different job characteristics to determine the quantitative approach to performance evaluation. If it is an engineering management department, its work is mainly an item-specific project management, which can be quantified according to the size of the project, how much is completed, and the quality of the project completion; some administrative departments, in addition to daily administrative work, There are often many important tasks that are closely linked to the school's development goals. These important tasks should also be given greater weight in the quantification of the work. In short, we must establish a set of quantifiable and easy-to-manage performance evaluation indicators system that combines the characteristics of the university itself and the characteristics of different departments and positions to integrate the school's overall development goals with the employees' goals and tasks. Let the staff have a good expectation of their own development.

\section{Conclusion}

The administration of colleges and universities is an important part of the work of human resources in universities and a basic part of personnel work. The quality and effectiveness of administrative work are of great significance to the development of universities. The performance appraisal of the internal administrative work of colleges and universities has important significance for the personnel management of colleges and universities. To do a good job of assessment management can improve the efficiency of the administrative management department, improve the working level, and promote the development of colleges and universities. At present, there are still some problems in the performance appraisal of university administrative management in our country. This article analyzes and discusses this, and puts forward corresponding strengthening measures, which has certain practical significance for the performance appraisal of university administration.

\section{References}

[1] Liu Xicui, Yi Wenli. Thoughts on Performance Management System of Administrative Posts in Private Colleges and Universities [J]. Cultural and Educational Resources, 2010(6).

[2] Liu Bing, Guo Ran. The Construction of Performance Management System of University Administrative Management Based on Balanced Scorecard [J]. Higher Education Development and Evaluation, 2007(1).

[3] Su Qiubin, Yin Zi. Performance Evaluation Model of University Administrators Based on Experience and Boston Matrix Analysis Method [J]. Technology Market Economy, 2007(10).

[4] Wang Yufeng. Research on the performance evaluation and improvement strategy of college administrators [J]. Journal of Hefei University of Technology: Social Science Edition, 2012(5).

[5] Zhou Wei. On the Performance Appraisal of University Administrative Staff [J]. Journal of Southern Yangtze University: Humanities and Social Science Edition, 2006(6) 